\title{
Insights into the function of tegument proteins from the varicella zoster virus
}

\author{
WANG Wei ${ }^{1}$, CHENG Tong $^{1}$, ZHU Hua $^{2} \&$ XIA NingShao ${ }^{1 *}$ \\ ${ }^{1}$ State Key Laboratory of Molecular Vaccinology and Molecular Diagnostics, National Institute of Diagnostics and Vaccine Development in \\ Infectious Diseases, School of Life Science, Xiamen University, Xiamen 361102, China; \\ ${ }^{2}$ Department of Microbiology and Molecular Genetics, New Jersey Medical School, Rutgers University, Newark NJ 07101, USA
}

Received April 7, 2015; accepted May 20, 2015; published online July 23, 2015

\begin{abstract}
Chickenpox (varicella) is caused by primary infection with varicella zoster virus (VZV), which can establish long-term latency in the host ganglion. Once reactivated, the virus can cause shingles (zoster) in the host. VZV has a typical herpesvirus virion structure consisting of an inner DNA core, a capsid, a tegument, and an outer envelope. The tegument is an amorphous layer enclosed between the nucleocapsid and the envelope, which contains a variety of proteins. However, the types and functions of VZV tegument proteins have not yet been completely determined. In this review, we describe the current knowledge on the multiple roles played by VZV tegument proteins during viral infection. Moreover, we discuss the VZV tegument protein-protein interactions and their impact on viral tissue tropism in SCID-hu mice. This will help us develop a better understanding of how the tegument proteins aid viral DNA replication, evasion of host immune response, and pathogenesis.
\end{abstract}

varicella zoster virus, VZV, tegument

Citation: Wang W, Cheng T, Zhu H, Xia NS. Insights into the function of tegument proteins from the varicella zoster virus. Sci China Life Sci, 2015, 58: 739-749, doi: 10.1007/s11427-015-4887-3

Varicella zoster virus (VZV), which belongs to the alphaherpesvirus subfamily of the Herpesviridae family, causes chickenpox (varicella) in children during primary infection and can establish long-term latency in the dorsal root ganglia (DRG) or cranial nerve sensory ganglia [1]. Subsequent reactivation of latent VZV may cause shingles (zoster) [1,2]. In addition, VZV infection may lead to serious complications such as encephalitis, meningitis, myelitis, conjunctivitis, and postherpetic neuralgia, which is most common. The latter condition is a painful, refractory disease that can seriously affect a patient's quality of life [3-6]. VZV virions, like all the other herpesviruses, are composed of a DNA core, a capsid, a tegument, and an envelope (Figure 1). The innermost layer of these virions is a nucleocapsid containing the VZV DNA genome and the outermost

*Corresponding author (email: nsxia@xmu.edu.cn) layer is an envelope that is derived from the host cell membranes and contains viral envelope glycoproteins. Between the nucleocapsid and envelope is an amorphous protein layer known as the tegument. Herpesvirus tegument proteins have been shown to play a number of key roles during viral infection. These functions include the intracellular transport of virus particles [7-16], viral assembly, and egress [17-30], regulation of viral and host cell gene transcription and protein expression [31-43], as well as viral immune evasion [41,44-47].

The VZV genome is a double-stranded DNA molecule, which is approximately $125 \mathrm{~kb}$ in length, containing at least 70 open reading frames (ORFs) [1,48]. Although VZV has the smallest genome in the herpesvirus family, research on VZV protein functions and molecular mechanisms of VZV pathogenesis has lagged behind comparable research on other herpesviruses such as the herpes simplex virus-1 

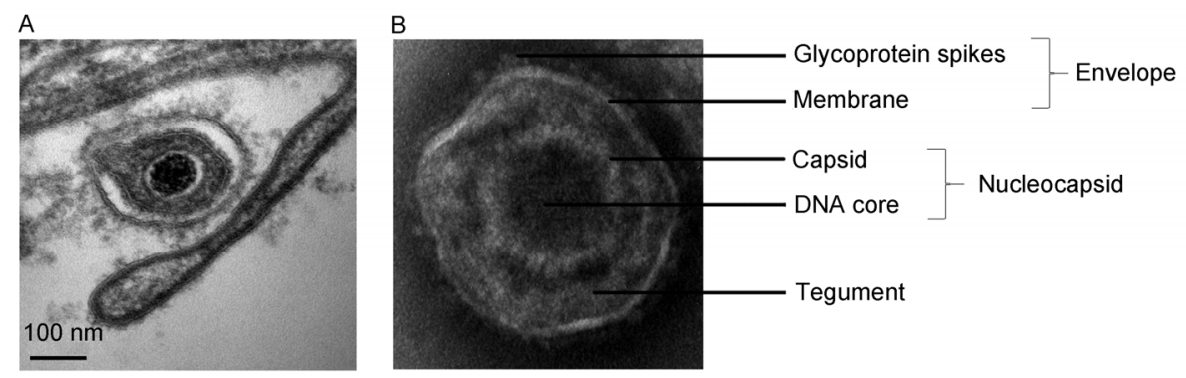

Figure 1 Electron micrograph of VZV. A, Extracellular VZV virion seen by TEM at a magnification of 30,000x. B, VZV virion structure.

(HSV-1) and the pseudorabies virus (PRV). One issue in analyzing the types and relative amounts of VZV tegument proteins is the strong cell-associated nature of VZV, which makes it very difficult to obtain mature VZV virions in sufficient quantity and purity for mass spectrometry analysis. Currently, both types and functions of VZV tegument proteins are mainly predicted from their HSV-1 homologues, which have already been identified and relatively well characterized (Table 1). Recent advances in bacterial artificial chromosome (BAC) technology have made genetic manipulation of the VZV genome more efficient, which greatly facilitates studies on functions of VZV genes and their products, virus-host interactions in VZV pathogenesis, as well as the design and development of new antiviral strategies and novel vaccines against VZV [49-51]. Additionally, in vivo studies of VZV pathogenesis have been aided by the development and use of the SCID-hu mouse model, which helps to overcome the strict species specificity of VZV and the corresponding lack of appropriate animal models for this research [50,51]. Current studies have shown that VZV tegument proteins also play important roles in VZV infection. Here we review recent progress in functional characterization of VZV tegument proteins as well as insights into the mechanism of VZV pathogenesis gained from these studies.

\section{VZV immediate early (IE) protein within the tegument}

The VZV genome encodes for at least three IE proteins, namely, IE4 (encoded by orf4), IE62 (encoded by orf62 and orf71), and IE63 (encoded by orf63 and orf70). Orf62 and orf63 in the internal repeat region of the genome are duplicated in the terminal repeat region as orf 71 and $\operatorname{orf} 70$, respectively [48]. VZV IE proteins IE4, IE62, and IE63 have all been identified as structural components of VZV virions and are likely located within the tegument layer according to protein content analysis of purified VZV virions [52,53]. In addition, VZV-encoded ORF61 protein is the functional homolog of HSV-1 IE protein ICP0, and thus, is a putative VZV IE protein. However, ORF61 is not virion-associated [52].
The interplay between IE proteins and other viral or cellular factors during VZV infection implicates VZV IE proteins as important regulators of viral and host gene transcription and expression [54-59]. In addition, VZV IE proteins are also involved in host immune evasion. For example, IE62 is capable of modulating host innate immune signaling by antagonizing activation of interferon response factor 3 (IRF3) [60]; IE63 can suppress the antiviral activity induced by interferon- $\alpha$ (IFN- $\alpha$ ) via inhibition of phosphorylation of the $\alpha$ subunit of eukaryotic initiation factor 2 (eIF-2 $\alpha$ ) [61]. Thus, when VZV enters the cell, IE proteins in the tegument are presumed to be released into the cytoplasm along with the capsid and may be further transported into the nucleus. These proteins could then aid in host immune suppression as well as activation of viral gene transcription and expression, thereby promoting the efficient replication and cell-to-cell spread of VZV.

In early studies of mechanisms underlying VZV latency and reactivation, IE proteins IE4, IE62, and IE63 were found to be expressed and show a predominantly cytoplasmic distribution in latently infected neurons [62-64]. In contrast, IE proteins, except IE4, are distributed mainly in the nucleus of cells during lytic VZV infection. Therefore, it is speculated that these IE proteins are sequestered from the nucleus during VZV latency, thereby limiting their role in gene transactivation and VZV replication [64]. Furthermore, IE4 and IE63 were also found to be essential for the establishment of VZV latency in a cotton rat model infected with VZV gene deletion mutants $[65,66]$. However, the role of VZV IE proteins expressed during latency remains elusive.

VZV deletion mutants for orf4, orf62/orf71, and orf63/orf70 fail to replicate in cell culture in vitro, in human skin organ culture (SOC) ex vivo, and in SCID-hu skin xenografts in vivo, respectively. Thus, these genes appear essential for VZV propagation $[57,58,67,68]$. Moreover, at least one copy of the duplicated IE62 or IE63 genes is required for VZV replication [57,68]. However, IE62 gene expression at an ectopic site in the VZV genome of a dual orf62/orf71 deletion mutant permits viral replication in cell culture but fails to restore virus infectivity in human skin implants in SCID-hu mice. This indicates the existence of regulatory regions at the native site of orf62 and/or orf7l, 
Table 1 VZV putative tegument proteins and their functions ${ }^{\text {a) }}$

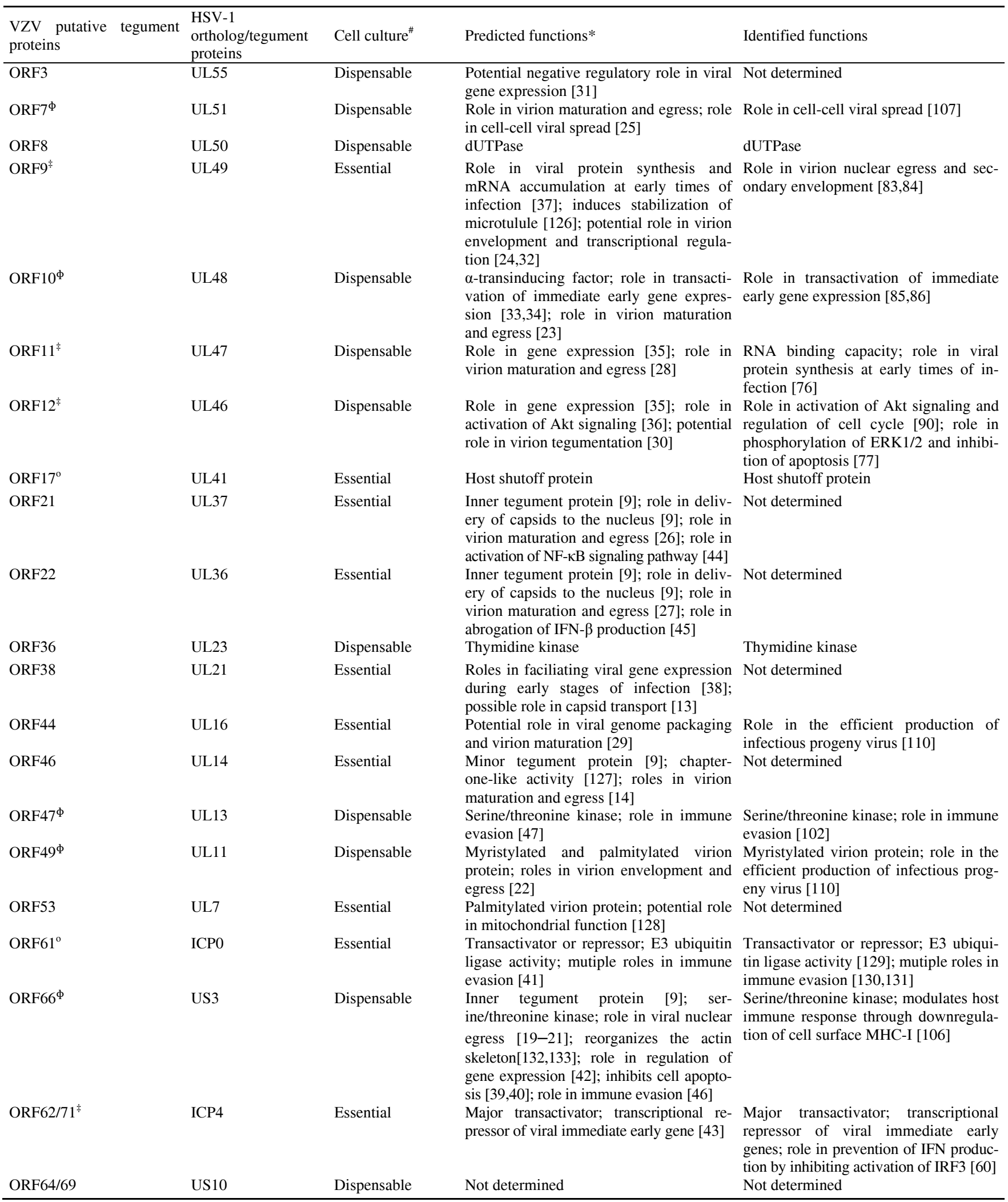

a) *, Functions of VZV putative tegument proteins were predicted based on charateristics of their homologous counterparts in HSV-1. \#, Functions in cell culture were determined using VZV mutants null for genes encoding putative tegument proteins. o, the protein is proved not virion-associated. ${ }^{\phi}$, the protein is proved virion-associated but its localization within the tegument of virion has not been confirmed. $\ddagger$, the protein is proved as a tegument protein in $\mathrm{VZV}$. 
which may affect the functions of adjacent genes [57]. In addition, it has been found that IE62 of parental Oka VZV (P-Oka) has stronger transactivation activity than that of the Oka vaccine strain (V-Oka), which is due to multiple mutations within orf62 in the vaccine virus and may contribute to attenuation of V-Oka in skin [69-72]. Overall, the gene products of the major transactivator IE62, as well as its gene sequence and precise position in VZV genome play a pivotal role in VZV skin pathogenesis. In contrast, infectivity of a dual orf63/orf70 deletion mutant can be restored to that of the wild type in culture as well as in skin and thymus/liver ( $\mathrm{T}$ cell) xenografts in SCID-hu mice by introducing one copy of orf63 into an ectopic site in the VZV genome [68]. Therefore, it is the gene product of orf63 rather than its gene sequence at the native site that performs functions in VZV pathogenesis. Further studies were carried out with the aim of identifying functional domains of IE63. It was demonstrated that mutations of IE63 phosphorylation sites at serine 165 and 173 result in loss of VZV infectivity. On the other hand, a single alanine substitution at serine 181, serine 185 , or threonine 171 , which are also phosphorylation sites of IE63, impairs VZV replication both in culture and in skin implants in SCID-hu mice but has no effect on viral infectivity in T cells in vivo [73]. These data suggest that phosphorylation of IE63 by viral and/or cellular kinases is critical for VZV pathogenesis in skin, but the regulatory mechanism of IE63 phosphorylation and its function remain to be defined.

\section{A conserved gene cluster of VZV containing orf9 to orf12}

VZV orf9, orf10, orf11, and orf12 form a conserved gene cluster, which is located in the unique long region of the VZV genome [74]. Their homologous HSV-1 counterparts encode virus tegument proteins that are important for viral replication [75], and therefore proteins encoded by this gene cluster are putative VZV tegument proteins. To date, VZV ORF10 has been shown to be a component of the virus particle through western blot analysis of gradient-purified virions [53], while ORF9, ORF11, and ORF12 are detected in the tegument of virions using immunogold electron microscopy [74,76,77].

Orf9, which encodes a viral structural protein, is one of the most abundantly transcribed genes during VZV infection [78,79], and is essential for VZV growth both in vitro and in vivo [67,74]. However, the homologue of VZV orf9 in HSV-1 and PRV is dispensable for virus replication [80,81]. Thus, it is likely that orf9 differs from its homologues in its function during viral infection. Currently, VZV ORF9 has been reported to have several functions. For instance, ORF9 is predicted to orchestrate the assembly of VZV virus particles by recruiting VZV tegument proteins, including IE62, IE4, IE63, and ORF47 which form a com- plex with IE62 during viral infection, on the microtubule network [82]. ORF9 has also been shown to interact with VZV glycoprotein E (gE), which is not part of the ORF9-IE62-tubulin complex, but may be involved in secondary envelopment [74]. Lastly, ORF9 has been implicated in VZV formation and egress, and this appears to be mediated through VZV ORF47 kinase-dependent phosphorylation of ORF9 [83]. According to the latest report, deletion of the acidic cluster corresponding to amino acid (aa) 85 to 93 of ORF9, which contains the ORF47 phosphorylation consensus sequence, disrupts interactions between ORF9 and ORF47 as well as phosphorylation of ORF9. This deletion also causes the nuclear accumulation of ORF9 and ORF47, and most importantly, results in accumulation of primary enveloped VZV capsids in the perinuclear space due to a de-envelopment defect [84]. Therefore, it seems that ORF9 also regulates virus nuclear egress.

ORF10 is capable of transactivating the VZV IE62 promoter and plays a significant role in the initiation of VZV infection [85,86]. Orf10 is not essential for VZV replication in culture and in $\mathrm{T}$ cells in vivo, but deletion of orf10 impairs VZV replication in skin ex vivo and in vivo [67,87]. In addition, upstream stimulatory factor (USF), which is identified as a cellular transcription factor, binds specifically to the consensus sequence within the promoter region of orf10 and is important for optimal transactivation activity of IE62. Deletion of the USF binding site in the orf10 promoter impairs the virus infectivity in skin xenografts in SCID-hu mice, which is consistent with the phenotype of the full-length orf10 deletion mutant [88]. Therefore, USF is a cellular determinant of VZV virulence, which is required for VZV replication in human skin in vivo. In short, ORF10 is involved in the regulation of viral and host gene expression, which is mediated by VZV IE62 and cellular USF, and is one of the determinants of VZV pathogenesis in skin in vivo.

Like orf10, orf11 is not essential for VZV growth in culture, but deletion of orf11 impairs viral infectivity severely in SCID-hu skin xenografts. Therefore, VZV ORF11 is also a determinant of VZV virulence in skin [74]. Further studies have been carried out to investigate the exact function of ORF11 in VZV infection. ORF11 was identified as a RNA binding protein with a conserved RNA-binding domain. However, knockout of this RNA-binding site does not affect VZV virulence both in vitro and in vivo [76]. Recently, ORF11 has been characterized to interact with ORF9, and mutation of the ORF9 binding site in ORF11 impairs VZV virulence in skin in vivo as severely as the deletion of orf11 [89]. These data implicate that interactions between ORF11 and ORF9 play a key role in the function of ORF11 as a virulence determinant of VZV skin pathogenesis.

Orf12 is a non-essential gene for VZV growth both in vitro and in vivo [67,74], but ORF12 still contributes to optimal VZV infection. For example, ORF12 activates the $\mathrm{PI} 3 \mathrm{~K} / \mathrm{Akt} / \mathrm{GSK}-3 \beta$ signaling pathway and thus regulates 
host cell cycle progression [90]; ORF12 also activates ERK1/2 and p38 and inhibits apoptosis of the infected host cell [77]. In summary, orf9-12 gene cluster plays a crucial role in VZV replication. Orf9 is essential for VZV growth both in vitro and in vivo. Although orf10 and orf11 are dispensable for VZV replication in culture, they are both essential for VZV virulence in skin implants in SCID-hu mice. It is further demonstrated that USF binding to the orflo promoter and interactions between ORF9 and ORF11 are likely part of the mechanism underlying VZV pathogenesis in skin. On the other hand, ORF12, which is not essential for VZV replication, is able to activate certain cellular signaling pathways and promote VZV infection.

\section{VZV serine/threonine kinases, ORF47 and ORF66}

The VZV genome encodes two types of serine/threonine kinases, ORF47 and ORF66 [91]. Both proteins are known to be virion-associated and are putative VZV tegument proteins based on the characteristics of their homologues in the alphaherpesvirus subfamily [75,92,93]. Orf47 and orf66 are both dispensable for VZV growth in culture. However, the orf47 deletion mutant fails to replicate both in skin and in $\mathrm{T}$ cells in SCID-hu mice, while knockout of orf66 impairs VZV virulence in T cells but has almost no effect on virulence in skin in vivo [94-96]. In addition, mutation of the kinase motif of ORF47 and ORF66 produces phenotypes that are similar to their full-length gene knockout mutants [97,98]. Therefore, kinase activities of ORF47 and ORF66 are likely to be responsible for VZV virulence and tissue tropism.

To date, putative VZV tegument proteins ORF9, IE62, and IE63 are proven substrates of VZV ORF47 kinase $[83,99]$. As mentioned above, ORF47 binding and phosphorylation of ORF9 as well as IE63 is crucial for VZV replication $[73,83,84]$. On the other hand, although kinase activities of ORF47 are of great importance for VZV infection in vivo, protein-protein interactions and complex formation between ORF47 and IE62 have been proven essential for VZV replication in human skin in vivo in a further study $[97,100]$. ORF47 also phosphorylates the viral envelope protein $\mathrm{gE}$ [101]. When orf47 is deleted, endocytosed $\mathrm{gE}$ will be phosphorylated by a cellular kinase, casein kinase II (CKII), lose its localization in the trans-Golgi network (TGN) and recycle to the plasma membrane. This is likely the cause of increased cell-to-cell spread and larger syncytia formation observed in cells infected with the orf47 knockout mutant. Further, ORF47 also helps VZV to evade host immune responses through inhibition of IRF3 activation [102].

ORF66 phosphorylates VZV major transactivator IE62, which results in nuclear export and cytoplasmic accumulation of IE62 during late-stage VZV infection [103,104].
This is in contrast to ORF47-mediated IE62 phosphorylation, which does not affect IE62 nuclear localization [104]. Therefore, it is suggested that VZV ORF66 kinase can regulate IE62 nuclear functions by affecting IE62 subcellular localization. Both ORF66 and IE62 are expressed exclusively in the cytoplasm of infected neurons during latency, and thus, ORF66-mediated cytoplasmic sequestration of IE62 is predicted as one mechanism that inhibits IE62 transactivation activities and helps VZV stay dormant in neurons [105]. In addition, ORF66-mediated nuclear exclusion of IE62 is also required for virion incorporation of IE62 [93]. Further, ORF66 plays a role in VZV immune evasion. ORF66 can affect the intracellular transport of major histocompatibility complex class I (MHC-1) through the Golgi complex, leading to the downregulation of cell-surface MHC-1expression and thereby affecting viral antigen presentation [106].

\section{ORF7, the first known determinant of VZV virulence in human neuronal cells}

ORF7 is a virion-associated protein and may be a part of the tegument given its homologue protein UL51 in HSV-1 [75,107]. Like the HSV-1 ul51 gene, orf7 is dispensable for VZV growth in culture, however, ORF7 seems to affect VZV in vitro growth in a cell type-specific manner. For instance, deletion of orf7 has no effect on VZV growth in a human melanoma cell line MeWo. Conversely, orf7 knockout mutant produces smaller plaque sizes and slower growth kinetics than wild-type virus in a human diploid retinal pigment epithelial (RPE) cell line ARPE-19, suggesting defects in cell-to-cell spread [67,107]. Further, it is demonstrated that deletion of orf7 impairs VZV virulence in ex vivo human skin, and thus, ORF7 is recognized as one of the virulence factors required for VZV skin infection [67]. Meanwhile, the orf7 knockout mutant is severely impaired in its ability to grow in differentiated SH-SY5Y human neuroblastoma cells and normal human neuronal cells derived from human embryonic stem cells (hESC) in vitro. The same is true in human DRG ex vivo and in vivo, in contrast to the robust infection by wild type virus. Therefore, orf7 is reported to be the first full-length gene responsible for VZV virulence in neuronal cells [107]. Subsequently, deletion of VZV orf7 was shown not to prevent axonal infection and retrograde transport of virus particles to the neuronal somata in hESC-derived neurons in vitro [108]. However, viral and host gene transcription and protein expression have not yet been evaluated in these VZV-infected hESC-derived neuronal cells. Thus, it is unknown whether the orf7 knockout mutant remains latent or begins to replicate and produce progeny viruses. In summary, although ORF7 has dual roles as virulence determinants in human skin and in DRG in vivo, the underlying mechanism has yet to be studied. 


\section{$5 \quad$ VZV ORF44 and ORF49}

ORF44 and ORF49 are both putative tegument proteins of VZV according to homology-based predictions [75]. However, only ORF49 has been shown to be a component of VZV virions [109]. Like orf7, orf49 is dispensable for VZV replication in vitro but has cell type-specific functions in cell-to-cell transmission of the virus. Deletion of orf49 impairs viral spread in MeWo cells but not in a human embryonic lung fibroblast diploid cell strain, MRC-5, in comparison to the growth of wild type virus in both cell types. Therefore, ORF49 is regarded as a cell-tropic factor of VZV in vitro but the underlying mechanism remains elusive [109]. Moreover, an orf49 knockout mutant also shows defective growth in SOC. Thus, it seems that ORF49 plays a significant role in VZV pathogenesis in human skin [67]. On the other hand, orf44 appears to be essential for VZV replication, however, characteristics of ORF44 has not yet been reported [67].

Recently, ORF44 and ORF49 have been shown to interact and form a complex [110]. The binding motifs of these two proteins have been identified to be a single phenylalanine residue at position 129 for ORF44 and four amino acids from positions 41-44 in the carboxyl-terminal half of ORF49. The interaction between ORF44 and ORF49 is required for VZV infection in vitro, and a substitution of phenylalanine for alanine at position 129 of ORF44 causes lethal defects in viral replication, which is consistent with the phenotype of an orf44 deletion mutant. Similarly, a VZV mutant with the aa 41-44 deletion shows defective viral growth in MeWo, which is comparable to that of an orf49 knockout virus. However, this ORF49 mutant has not been evaluated in the SCID-hu mouse model, and thus, the role of ORF44 and ORF49 interaction in VZV pathogenesis in vivo has yet to be elucidated.

\section{Other VZV tegument proteins of unknown function}

As with the proteins mentioned above, ORF3, ORF8, ORF17, ORF21, ORF22, ORF36, ORF38, ORF46, ORF53, and ORF64/69 are all putative VZV tegument proteins, among which only ORF17 is characterized as the virion host shut off (VHS) protein but it is not associated with VZV virions [75,111]. In a comprehensive study of VZV virulence in MeWo in vitro and in SOC ex vivo, ORF3, ORF8, ORF36, and ORF64/69 were shown to be dispensable, while ORF21, ORF22, ORF38, and ORF53 were shown to be essential for VZV infection [67]. Apart from this study, there have been few reports regarding these proteins and research on their roles in VZV infection is still lacking. However, it should be noted that their homologous counterparts in HSV-1 have proved to be very important for viral replication and growth $[9,13,14,26,27,31,38,44,45,127,128]$.

\section{Conclusion and perspectives}

VZV tegument proteins, like those of other herpesviruses, play multiple important roles at different stages of VZV infection, including regulation of viral and host gene expression, modulation of host immune response, and viral assembly and egress (Table 1 ). VZV tegument proteins are involved in a complicated network of interactions [112,113]. Some VZV tegument proteins have proved to be determinants of cell and tissue tropism and pathogenicity (Table 2).

Table 2 Tegument proteins required for VZV virulence in human skin, T cells and DRG in vivo in SCID-hu mouse model as well as their identified functional domains or motifs ${ }^{\text {a) }}$

\begin{tabular}{llll}
\hline Protein & Mutation description & Skin* & T cells* \\
\hline ORF7 & Deletion & $\times$ & $\mathrm{O}^{*}$ \\
ORF10 & Deletion & $\times$ & DRG \\
& Mutation of USF binding site & $\times$ & - \\
ORF11 & Deletion & $\times$ & - \\
& Mutation of ORF9 binding site & $\times$ & - \\
ORF47 & Deletion & $\times$ & $\times$ \\
& Mutation of kinase motif & $\times$ & - \\
ORF49 & Deletion & O & - \\
ORF66 & Deletion & O & - \\
ORF62/ORF71 & Deletion of the duplicate genes with ectopic IE62 expression & $\times$ & - \\
ORF63/ORF70 & Mutation of phosphorylation sites S181, S185 or T171 & $\times$ \\
\hline
\end{tabular}

a) *, Determinants of VZV virulence in human tissues were screened out using recombinant VZV variants and the SCID-hu mouse model. \$, Unpublished data from our lab. $\times$, no replication or impaired replication. $\mathrm{O}$, no effect. - , not determined. 
Nonetheless, only about half of these proteins have been studied to date, and great efforts are still required to characterize the functions of these proteins to improve our understanding of VZV pathogenesis.

VZV is highly homologous to HSV-1. Given this, the functions of VZV tegument proteins can be studied with particular reference to the research methods and experimental design for functional characterization of their HSV-1 counterparts. For example, the hESC-derived neuron model, together with time-lapse fluorescence microscopy, can be used to study the function of VZV tegument proteins in axonal infection and transport of virus particles. Similar systems have been widely used for functional studies of HSV-1 and PRV tegument proteins $[8,15,16]$. However, as mentioned above, only tegument protein ORF7 of VZV has been evaluated in this system [108]. Unlike HSV-1, VZV is highly cell-associated in cell culture and is highly species-specific so that research methods involving VZV have to be properly designed and executed to match its own characteristics. For example, in recent years, there has been concern about how tegument proteins become incorporated into the virion of herpesviruses. Although sufficient virions with high purity can be obtained and protein content in the tegument has been clarified in studies of HSV-1, the structure of the tegument appears amorphous using transmission electron microscopy (TEM) and cannot be determined at high resolution using cryo-electron tomography (cryo-ET) and cryo-electron microscopy (cryo-EM) due to the lack of radial symmetry [114-118]. However, accumulating evidence suggests that tegument proteins are incorporated into the virion orderly during assembly [18,119-124]. In addition, it is found that inner tegument proteins of HSV-1 and PRV recruit microtubule motors onto viral capsids and facilitate intracellular transport of virus particles [9,11]. As for $\mathrm{VZV}$, it is very difficult to purify large numbers of mature infectious virus particles for these studies due to its cell-associated nature. Therefore, the structure and protein composition of the VZV tegument as well as the interactions between the virus particle and the host cell remain to be investigated.

Currently, the combination of VZV BAC technology and the SCID-hu mouse model has significantly advanced our understanding of VZV pathogenesis in vivo. Due to the relatively high availability of fetal human skin and the simplicity of its subcutaneous transplantation, functions of VZV genes and their products are studied more comprehensively in skin xenografts in SCID-hu mice. In contrast, the availability of fetal thymus and liver and DRG tissue is limited, and it is difficult to transplant these tissues under the kidney capsule in SCID-hu mice. Thus, the SCID-hu mouse model with thymus/liver or DRG xenografts has not been used as widely as that with skin xenografts in VZV studies. Moreover, human skin can be used for VZV infection by almost 10 days post-transplant in SCID-hu mice. In contrast, DRG can be used for infection at nearly one month after transplantation, while it takes at least 3 months before thymus/liver ( $\mathrm{T}$ cells) xenograft can be used for VZV inoculation. So far, among VZV tegument proteins, only the two viral kinases, ORF47 and ORF66, have been shown to affect VZV T-cell tropism, while ORF7 is the first determinant of VZV virulence reported to affect viral neuroninvasion [94,107]. Thus, the function of many tegument proteins in VZV infection of $\mathrm{T}$ cells and neuronal cells remains to be determined.

Given that VZV tegument proteins are critical for VZV infection, they represent potential targets for VZV antiviral therapy. Although some of VZV tegument proteins are dispensable in culture, they are determinants of VZV tissue tropism and virulence in vivo. For example, deletion of VZV tegument ORF7 can impair viral virulence both in human skin and neurons, which may disrupt the ability of the virus to cause chickenpox and herpes zoster [67,107]. The current VZV vaccine is a live attenuated viral vaccine whose administration is generally regarded as safe [125]. However, the mechanism underlying attenuation of this vaccine virus remains unclear. Therefore, deletion of virulence determinants in VZV may generate a safer live vaccine candidate, which may have a significant impact on human lives and public health.

This work was supported by the Fujian Technological Innovation Platform Fund (2014Y2101), and the Xiamen City Municipal Platform Fund (3502Z201410045, 3502Z20131001).

1 Cohen JI, Straus SE, Arvin AM. Fields virology. 5th ed. Philadelphia: Lippincott Williams \& Wilkins, 2007. 2773-2818

2 Gilden DH, Kleinschmidt-DeMasters BK, LaGuardia JJ, Mahalingam R, Cohrs RJ. Neurologic complications of the reactivation of varicella-zoster virus. N Engl J Med, 2000, 342: 635-645

3 Lukas K, Edte A, Bertrand I. The impact of herpes zoster and post-herpetic neuralgia on quality of life: patient-reported outcomes in six european countries. Z Gesundh Wiss, 2012, 20: 441-451

4 Weinke T, Edte A, Schmitt S, Lukas K. Impact of herpes zoster and post-herpetic neuralgia on patients' quality of life: a patient-reported outcomes survey. Z Gesundh Wiss, 2010, 18: 367-374

5 Johnson RW, Bouhassira D, Kassianos G, Leplege A, Schmader KE, Weinke T. The impact of herpes zoster and post-herpetic neuralgia on quality-of-life. BMC Med, 2010, 8: 37

6 Drolet M, Brisson M, Schmader KE, Levin MJ, Johnson R, Oxman MN, Patrick D, Blanchette C, Mansi JA. The impact of herpes zoster and postherpetic neuralgia on health-related quality of life: a prospective study. CMAJ, 2010, 182: 1731-1736

7 Granzow H, Klupp BG, Mettenleiter TC. Entry of pseudorabies virus: an immunogold-labeling study. J Virol, 2005, 79: 3200-3205

8 Luxton GW, Haverlock S, Coller KE, Antinone SE, Pincetic A, Smith GA. Targeting of herpesvirus capsid transport in axons is coupled to association with specific sets of tegument proteins. Proc Natl Acad Sci USA, 2005, 102: 5832-5837

9 Radtke K, Kieneke D, Wolfstein A, Michael K, Steffen W, Scholz T, Karger A, Sodeik B. Plus- and minus-end directed microtubule motors bind simultaneously to herpes simplex virus capsids using different inner tegument structures. PLoS Pathog, 2010, 6: e1000991

10 Sandbaumhuter M, Dohner K, Schipke J, Binz A, Pohlmann A, Sodeik B, Bauerfeind R. Cytosolic herpes simplex virus capsids not only require binding inner tegument protein pUL36 but also pUL37 for active transport prior to secondary envelopment. Cell Microbiol, 
2013, 15: 248-269

11 Wolfstein A, Nagel CH, Radtke K, Dohner K, Allan VJ, Sodeik B. The inner tegument promotes herpes simplex virus capsid motility along microtubules in vitro. Traffic, 2006, 7: 227-237

12 Coller KE, Smith GA. Two viral kinases are required for sustained long distance axon transport of a neuroinvasive herpesvirus. Traffic, 2008, 9: 1458-1470

13 Takakuwa H, Goshima F, Koshizuka T, Murata T, Daikoku T, Nishiyama Y. Herpes simplex virus encodes a virion-associated protein which promotes long cellular processes in over-expressing cells. Genes Cells, 2001, 6: 955-966

14 Yamauchi Y, Kiriyama K, Kubota N, Kimura H, Usukura J, Nishiyama Y. The UL14 tegument protein of herpes simplex virus type 1 is required for efficient nuclear transport of the alpha transinducing factor VP16 and viral capsids. J Virol, 2008, 82: 1094-1106

15 Smith GA, Pomeranz L, Gross SP, Enquist LW. Local modulation of plus-end transport targets herpesvirus entry and egress in sensory axons. Proc Natl Acad Sci USA, 2004, 101: 16034-16039

16 Antinone SE, Smith GA. Retrograde axon transport of herpes simplex virus and pseudorabies virus: a live-cell comparative analysis. $\mathrm{J}$ Virol, 2010, 84: 1504-1512

17 Klupp BG, Granzow H, Mettenleiter TC. Effect of the pseudorabies virus US3 protein on nuclear membrane localization of the UL34 protein and virus egress from the nucleus. J Gen Virol, 2001, 82: 2363-2371

18 Klupp BG, Granzow H, Mundt E, Mettenleiter TC. Pseudorabies virus UL37 gene product is involved in secondary envelopment. J Virol, 2001, 75: 8927-8936

19 Mou F, Forest T, Baines JD. US3 of herpes simplex virus type 1 encodes a promiscuous protein kinase that phosphorylates and alters localization of lamin A/C in infected cells. J Virol, 2007, 81: 6459-6470

20 Reynolds AE, Ryckman BJ, Baines JD, Zhou Y, Liang L, Roller RJ. UL31 and UL34 proteins of herpes simplex virus type 1 form a complex that accumulates at the nuclear rim and is required for envelopment of nucleocapsids. J Virol, 2001, 75: 8803-8817

21 Mou F, Wills E, Baines JD. Phosphorylation of the UL31 protein of herpes simplex virus 1 by the US3-encoded kinase regulates localization of the nuclear envelopment complex and egress of nucleocapsids. J Virol, 2009, 83: 5181-5191

22 Baines JD, Roizman B. The UL11 gene of herpes simplex virus 1 encodes a function that facilitates nucleocapsid envelopment and egress from cells. J Virol, 1992, 66: 5168-5174

23 Mossman KL, Sherburne R, Lavery C, Duncan J, Smiley JR. Evidence that herpes simplex virus VP16 is required for viral egress downstream of the initial envelopment event. J Virol, 2000, 74: 6287-6299

24 Brignati MJ, Loomis JS, Wills JW, Courtney RJ. Membrane association of VP22, a herpes simplex virus type 1 tegument protein. J Virol, 2003, 77: 4888-4898

25 Nozawa N, Kawaguchi Y, Tanaka M, Kato A, Kato A, Kimura H, Nishiyama Y. Herpes simplex virus type 1 UL51 protein is involved in maturation and egress of virus particles. J Virol, 2005, 79: 6947-6956

26 Desai P, Sexton GL, McCaffery JM, Person S. A null mutation in the gene encoding the herpes simplex virus type 1 UL37 polypeptide abrogates virus maturation. J Virol, 2001, 75: 10259-10271

27 Desai PJ. A null mutation in the UL36 gene of herpes simplex virus type 1 results in accumulation of unenveloped DNA-filled capsids in the cytoplasm of infected cells. J Virol, 2000, 74: 11608-11618

28 Liu Z, Kato A, Shindo K, Noda T, Sagara H, Kawaoka Y, Arii J, Kawaguchi Y. Herpes simplex virus 1 UL47 interacts with viral nuclear egress factors UL31, UL34, and US3 and regulates viral nuclear egress. J Virol, 2014, 88: 4657-4667

29 Starkey JL, Han J, Chadha P, Marsh JA, Wills JW. Elucidation of the block to herpes simplex virus egress in the absence of tegument protein UL16 reveals a novel interaction with VP22. J Virol, 2014, 88: 110-119

30 Murphy MA, Bucks MA, O'Regan KJ, Courtney RJ. The HSV-1 tegument protein pUL46 associates with cellular membranes and viral capsids. Virology, 2008, 376: 279-289

31 Block T, Jordan R, Farkas DH, Hughes RG Jr. Inhibition of transient gene expression with plasmids encoding herpes simplex virus type 1 UL55 and alpha genes. J Gen Virol, 1991, 72: 131-141

32 Yu X, Li W, Liu L, Che Y, Cun W, Wu W, He C, Shao C, Li Q. Functional analysis of transcriptional regulation of herpes simplex virus type 1 tegument protein VP22. Sci China C Life Sci, 2008, 51: 966-972

33 Campbell ME, Palfreyman JW, Preston CM. Identification of herpes simplex virus DNA sequences which encode a trans-acting polypeptide responsible for stimulation of immediate early transcription. J Mol Biol, 1984, 180: 1-19

34 Pellett PE, McKnight JL, Jenkins FJ, Roizman B. Nucleotide sequence and predicted amino acid sequence of a protein encoded in a small herpes simplex virus DNA fragment capable of trans-inducing $\alpha$ genes. Proc Natl Acad Sci USA, 1985, 82: 5870-5874

35 Zhang Y, McKnight JL. Herpes simplex virus type 1 UL46 and UL47 deletion mutants lack VP11 and VP12 or VP13 and VP14, respectively, and exhibit altered viral thymidine kinase expression. J Virol, 1993, 67: 1482-1492

36 Wagner MJ, Smiley JR. Herpes simplex virus requires VP11/12 to activate Src family kinase-phosphoinositide 3-kinase-Akt signaling. J Virol, 2011, 85: 2803-2812

37 Duffy C, Mbong EF, Baines JD. VP22 of herpes simplex virus 1 promotes protein synthesis at late times in infection and accumulation of a subset of viral mrnas at early times in infection. J Virol, 2009, 83: 1009-1017

38 Mbong EF, Woodley L, Frost E, Baines JD, Duffy C. Deletion of UL21 causes a delay in the early stages of the herpes simplex virus 1 replication cycle. J Virol, 2012, 86: 7003-7007

39 Wang X, Patenode C, Roizman B. US3 protein kinase of HSV-1 cycles between the cytoplasm and nucleus and interacts with programmed cell death protein 4 (PDCD4) to block apoptosis. Proc Natl Acad Sci USA, 2011, 108: 14632-14636

40 Benetti L, Roizman B. In transduced cells, the US3 protein kinase of herpes simplex virus 1 precludes activation and induction of apoptosis by transfected procaspase 3. J Virol, 2007, 81: 10242-10248

41 Smith MC, Boutell C, Davido DJ. HSV-1 ICP0: paving the way for viral replication. Future Virol, 2011, 6: 421-429

42 Poon AP, Gu H, Roizman B. ICP0 and the US3 protein kinase of herpes simplex virus 1 independently block histone deacetylation to enable gene expression. Proc Natl Acad Sci USA, 2006, 103: 9993-9998

43 Lium EK, Panagiotidis CA, Wen X, Silverstein S. Repression of the $\alpha 0$ gene by ICP 4 during a productive herpes simplex virus infection. J Virol, 1996, 70: 3488-3496

44 Liu X, Fitzgerald K, Kurt-Jones E, Finberg R, Knipe DM. Herpesvirus tegument protein activates NF- $\kappa B$ signaling through the TRAF6 adaptor protein. Proc Natl Acad Sci USA, 2008, 105: 11335-11339

45 Wang S, Wang K, Li J, Zheng C. Herpes simplex virus 1 ubiquitin-specific protease UL36 inhibits beta interferon production by deubiquitinating TRAF3. J Virol, 2013, 87: 11851-11860

46 Liang L, Roizman B. Expression of gamma interferon-dependent genes is blocked independently by virion host shutoff RNase and by US3 protein kinase. J Virol, 2008, 82: 4688-4696

47 Shibaki T, Suzutani T, Yoshida I, Ogasawara M, Azuma M. Participation of type I interferon in the decreased virulence of the UL13 gene-deleted mutant of herpes simplex virus type 1. J Interferon Cytokine Res, 2001, 21: 279-285

48 Cohen JI. The varicella-zoster virus genome. Curr Top Microbiol Immunol, 2010, 342: 1-14

49 Nagaike K, Mori Y, Gomi Y, Yoshii H, Takahashi M, Wagner M, Koszinowski U, Yamanishi K. Cloning of the varicella-zoster virus genome as an infectious bacterial artificial chromosome in Escherichia coli. Vaccine, 2004, 22: 4069-4074

50 Zhang Z, Rowe J, Wang W, Sommer M, Arvin A, Moffat J, Zhu H. Genetic analysis of varicella-zoster virus ORF0 to ORF4 by use of a 
novel luciferase bacterial artificial chromosome system. J Virol, 2007, 81: 9024-9033

51 Zerboni L, Sen N, Oliver SL, Arvin AM. Molecular mechanisms of varicella zoster virus pathogenesis. Nat Rev Microbiol, 2014, 12: 197-210

52 Kinchington PR, Bookey D, Turse SE. The transcriptional regulatory proteins encoded by varicella-zoster virus open reading frames (ORFs) 4 and 63, but not ORF 61, are associated with purified virus particles. J Virol, 1995, 69: 4274-4282

53 Kinchington PR, Hougland JK, Arvin AM, Ruyechan WT, Hay J. The varicella-zoster virus immediate-early protein IE62 is a major component of virus particles. J Virol, 1992, 66: 359-366

54 Defechereux P, Melen L, Baudoux L, Merville-Louis MP, Rentier B, Piette J. Characterization of the regulatory functions of varicella-zoster virus open reading frame 4 gene product. J Virol, 1993, 67: 4379-4385

55 Moriuchi H, Moriuchi M, Smith HA, Cohen JI. Varicella-zoster virus open reading frame 4 protein is functionally distinct from and does not complement its herpes simplex virus type 1 homolog, ICP27. J Virol, 1994, 68: 1987-1992

56 Perera LP, Mosca JD, Sadeghi-Zadeh M, Ruyechan WT, Hay J. The varicella-zoster virus immediate early protein, IE62, can positively regulate its cognate promoter. Virology, 1992, 191: 346-354

57 Sato B, Ito H, Hinchliffe S, Sommer MH, Zerboni L, Arvin AM. Mutational analysis of open reading frames 62 and 71, encoding the varicella-zoster virus immediate-early transactivating protein, IE62, and effects on replication in vitro and in skin xenografts in the SCID-hu mouse in vivo. J Virol, 2003, 77: 5607-5620

58 Sato B, Sommer M, Ito H, Arvin AM. Requirement of varicella-zoster virus immediate-early 4 protein for viral replication. J Virol, 2003, 77: 12369-12372

59 Hoover SE, Cohrs RJ, Rangel ZG, Gilden DH, Munson P, Cohen JI. Downregulation of varicella-zoster virus (VZV) immediate-early ORF62 transcription by VZV ORF63 correlates with virus replication in vitro and with latency. J Virol, 2006, 80: 3459-3468

60 Sen N, Sommer M, Che X, White K, Ruyechan WT, Arvin AM. Varicella-zoster virus immediate-early protein 62 blocks interferon regulatory factor 3 (IRF3) phosphorylation at key serine residues: a novel mechanism of IRF3 inhibition among herpesviruses. J Virol, 2010, 84: 9240-9253

61 Ambagala AP, Cohen JI. Varicella-zoster virus IE63, a major viral latency protein, is required to inhibit the alpha interferon-induced antiviral response. J Virol, 2007, 81: 7844-7851

62 Debrus S, Sadzot-Delvaux C, Nikkels AF, Piette J, Rentier B. Varicella-zoster virus gene 63 encodes an immediate-early protein that is abundantly expressed during latency. J Virol, 1995, 69: 3240-3245

63 Kennedy PG, Grinfeld E, Bell JE. Varicella-zoster virus gene expression in latently infected and explanted human ganglia. J Virol, 2000, 74: 11893-11898

64 Lungu O, Panagiotidis CA, Annunziato PW, Gershon AA, Silverstein SJ. Aberrant intracellular localization of varicella-zoster virus regulatory proteins during latency. Proc Natl Acad Sci USA, 1998, 95: 7080-7085

65 Cohen JI, Cox E, Pesnicak L, Srinivas S, Krogmann T. The varicella-zoster virus open reading frame 63 latency-associated protein is critical for establishment of latency. J Virol, 2004, 78: 11833-11840

66 Cohen JI, Krogmann T, Ross JP, Pesnicak L, Prikhod'ko EA. Varicella-zoster virus ORF4 latency-associated protein is important for establishment of latency. J Virol, 2005, 79: 6969-6975

67 Zhang Z, Selariu A, Warden C, Huang G, Huang Y, Zaccheus O, Cheng T, Xia NS, Zhu H. Genome-wide mutagenesis reveals that ORF7 is a novel VZV skin-tropic factor. PLoS Pathog, 2010, 6: e1000971

68 Sommer MH, Zagha E, Serrano OK, Ku CC, Zerboni L, Baiker A, Santos R, Spengler M, Lynch J, Grose C, Ruyechan W, Hay J, Arvin AM. Mutational analysis of the repeated open reading frames, ORFs 63 and 70 and ORFs 64 and 69, of varicella-zoster virus. J Virol, 2001, 75: 8224-8239

69 Gomi Y, Imagawa T, Takahashi M, Yamanishi K. Comparison of
DNA sequence and transactivation activity of open reading frame 62 of Oka varicella vaccine and its parental viruses. Arch Virol Suppl, 2001, 17: 49-56

70 Cohrs RJ, Gilden DH, Gomi Y, Yamanishi K, Cohen JI. Comparison of virus transcription during lytic infection of the Oka parental and vaccine strains of varicella-zoster virus. J Virol, 2006, 80: 2076-2082

71 Argaw T, Cohen JI, Klutch M, Lekstrom K, Yoshikawa T, Asano Y, Krause PR. Nucleotide sequences that distinguish Oka vaccine from parental Oka and other varicella-zoster virus isolates. J Infect Dis, 2000, 181: 1153-1157

72 Gomi Y, Imagawa T, Takahashi M, Yamanishi K. Oka varicella vaccine is distinguishable from its parental virus in DNA sequence of open reading frame 62 and its transactivation activity. J Med Virol, 2000, 61: 497-503

73 Baiker A, Bagowski C, Ito H, Sommer M, Zerboni L, Fabel K, Hay J, Ruyechan W, Arvin AM. The immediate-early 63 protein of varicella-zoster virus: analysis of functional domains required for replication in vitro and for T-cell and skin tropism in the SCIDhu model in vivo. J Virol, 2004, 78: 1181-1194

74 Che X, Reichelt M, Sommer MH, Rajamani J, Zerboni L, Arvin AM. Functions of the ORF9-to-ORF12 gene cluster in varicella-zoster virus replication and in the pathogenesis of skin infection. J Virol, 2008, 82: 5825-5834

75 Loret S, Guay G, Lippe R. Comprehensive characterization of extracellular herpes simplex virus type 1 virions. J Virol, 2008, 82: 8605-8618

76 Che X, Oliver SL, Sommer MH, Rajamani J, Reichelt M, Arvin AM. Identification and functional characterization of the varicella zoster virus ORF11 gene product. Virology, 2011, 412: 156-166

77 Liu X, Li Q, Dowdell K, Fischer ER, Cohen JI. Varicella-Zoster virus ORF12 protein triggers phosphorylation of ERK1/2 and inhibits apoptosis. J Virol, 2012, 86: 3143-3151

78 Cohrs RJ, Hurley MP, Gilden DH. Array analysis of viral gene transcription during lytic infection of cells in tissue culture with Varicella-Zoster virus. J Virol, 2003, 77: 11718-11732

79 Kennedy PG, Grinfeld E, Craigon M, Vierlinger K, Roy D, Forster T, Ghazal P. Transcriptomal analysis of varicella-zoster virus infection using long oligonucleotide-based microarrays. J Gen Virol, 2005, 86: 2673-2684

80 Duffy C, Lavail JH, Tauscher AN, Wills EG, Blaho JA, Baines JD. Characterization of a UL49-null mutant: VP22 of herpes simplex virus type 1 facilitates viral spread in cultured cells and the mouse cornea. J Virol, 2006, 80: 8664-8675

81 Elliott G, Hafezi W, Whiteley A, Bernard E. Deletion of the herpes simplex virus VP22-encoding gene (UL49) alters the expression, localization, and virion incorporation of ICP0. J Virol, 2005, 79: 9735-9745

82 Cilloniz C, Jackson W, Grose C, Czechowski D, Hay J, Ruyechan WT. The varicella-zoster virus (VZV) ORF9 protein interacts with the IE62 major VZV transactivator. J Virol, 2007, 81: 761-774

83 Riva L, Thiry M, Bontems S, Joris A, Piette J, Lebrun M, Sadzot-Delvaux C. ORF9p phosphorylation by ORF47p is crucial for the formation and egress of varicella-zoster virus viral particles. J Virol, 2013, 87: 2868-2881

84 Riva L, Thiry M, Lebrun M, L'Homme L, Piette J, Sadzot-Delvaux C. Deletion of the ORF9p acidic cluster impairs the nuclear egress of varicella-zoster virus capsids. J Virol, 2014, 89: 2436-2441

85 Moriuchi H, Moriuchi M, Cohen JI. Proteins and cis-acting elements associated with transactivation of the varicella-zoster virus (VZV) immediate-early gene 62 promoter by VZV open reading frame 10 protein. J Virol, 1995, 69: 4693-4701

86 Moriuchi H, Moriuchi M, Straus SE, Cohen JI. Varicella-zoster virus open reading frame 10 protein, the herpes simplex virus VP16 homolog, transactivates herpesvirus immediate-early gene promoters. J Virol, 1993, 67: 2739-2746

87 Che X, Zerboni L, Sommer MH, Arvin AM. Varicella-zoster virus open reading frame 10 is a virulence determinant in skin cells but not in T cells in vivo. J Virol, 2006, 80: 3238-3248

88 Che X, Berarducci B, Sommer M, Ruyechan WT, Arvin AM. The 
ubiquitous cellular transcriptional factor USF targets the varicella-zoster virus open reading frame 10 promoter and determines virulence in human skin xenografts in SCIDhu mice in vivo. J Virol, 2007, 81: 3229-3239

89 Che X, Oliver SL, Reichelt M, Sommer MH, Haas J, Rovis TL, Arvin AM. ORF11 protein interacts with the ORF9 essential tegument protein in varicella-zoster virus infection. J Virol, 2013, 87: 5106-5117

90 Liu X, Cohen JI. Varicella-zoster virus ORF12 protein activates the phosphatidylinositol 3-kinase/Akt pathway to regulate cell cycle progression. J Virol, 2013, 87: 1842-1848

91 Gershburg E, Pagano JS. Conserved herpesvirus protein kinases. Biochim Biophys Acta, 2008, 1784: 203-212

92 Stevenson D, Colman KL, Davison AJ. Characterization of the putative protein kinases specified by varicella-zoster virus genes 47 and 66. J Gen Virol, 1994, 75: 317-326

93 Kinchington PR, Fite K, Seman A, Turse SE. Virion association of IE62, the varicella-zoster virus (VZV) major transcriptional regulatory protein, requires expression of the VZV open reading frame 66 protein kinase. J Virol, 2001, 75: 9106-9113

94 Moffat JF, Zerboni L, Sommer MH, Heineman TC, Cohen JI, Kaneshima H, Arvin AM. The ORF47 and ORF66 putative protein kinases of varicella-zoster virus determine tropism for human T cells and skin in the SCID-hu mouse. Proc Natl Acad Sci USA, 1998, 95: 11969-11974

95 Heineman TC, Cohen JI. The varicella-zoster virus (VZV) open reading frame 47 (ORF47) protein kinase is dispensable for viral replication and is not required for phosphorylation of ORF63 protein, the VZV homolog of herpes simplex virus ICP22. J Virol, 1995, 69: 7367-7370

96 Heineman TC, Seidel K, Cohen JI. The varicella-zoster virus ORF66 protein induces kinase activity and is dispensable for viral replication. J Virol, 1996, 70: 7312-7317

97 Besser J, Sommer MH, Zerboni L, Bagowski CP, Ito H, Moffat J, Ku CC, Arvin AM. Differentiation of varicella-zoster virus ORF47 protein kinase and IE62 protein binding domains and their contributions to replication in human skin xenografts in the SCID-hu mouse. J Virol, 2003, 77: 5964-5974

98 Schaap-Nutt A, Sommer M, Che X, Zerboni L, Arvin AM. ORF66 protein kinase function is required for T-cell tropism of varicella-zoster virus in vivo. J Virol, 2006, 80: 11806-11816

99 Kenyon TK, Lynch J, Hay J, Ruyechan W, Grose C. Varicella-zoster virus ORF47 protein serine kinase: characterization of a cloned, biologically active phosphotransferase and two viral substrates, ORF62 and ORF63. J Virol, 2001, 75: 8854-8858

100 Besser J, Ikoma M, Fabel K, Sommer MH, Zerboni L, Grose C, Arvin AM. Differential requirement for cell fusion and virion formation in the pathogenesis of varicella-zoster virus infection in skin and $\mathrm{T}$ cells. J Virol, 2004, 78: 13293-13305

101 Kenyon TK, Cohen JI, Grose C. Phosphorylation by the varicella-zoster virus ORF47 protein serine kinase determines whether endocytosed viral $\mathrm{gE}$ traffics to the trans-Golgi network or recycles to the cell membrane. J Virol, 2002, 76: 10980-10993

102 Vandevenne P, Lebrun M, El Mjiyad N, Ote I, Di Valentin E, Habraken Y, Dortu E, Piette J, Sadzot-Delvaux C. The varicella-zoster virus ORF47 kinase interferes with host innate immune response by inhibiting the activation of IRF3. PLoS One, 2011, 6: e16870

103 Eisfeld AJ, Turse SE, Jackson SA, Lerner EC, Kinchington PR. Phosphorylation of the varicella-zoster virus (VZV) major transcriptional regulatory protein IE62 by the VZV open reading frame 66 protein kinase. J Virol, 2006, 80: 1710-1723

104 Kinchington PR, Turse SE. Regulated nuclear localization of the varicella-zoster virus major regulatory protein, IE62. J Infect Dis, 1998, 178: S16-S21

105 Cohrs RJ, Gilden DH, Kinchington PR, Grinfeld E, Kennedy PG. Varicella-zoster virus gene 66 transcription and translation in latently infected human ganglia. J Virol, 2003, 77: 6660-6665

106 Eisfeld AJ, Yee MB, Erazo A, Abendroth A, Kinchington PR. Downregulation of class I major histocompatibility complex surface expression by varicella-zoster virus involves open reading frame 66 protein kinase-dependent and -independent mechanisms. J Virol, 2007, 81: 9034-9049

107 Selariu A, Cheng T, Tang Q, Silver B, Yang L, Liu C, Ye X, Markus A, Goldstein RS, Cruz-Cosme RS, Lin Y, Wen L, Qian H, Han J, Dulal K, Huang Y, Li Y, Xia NS, Zhu H. ORF7 of varicella-zoster virus is a neurotropic factor. J Virol, 2012, 86: 8614-8624

108 Grigoryan S, Kinchington PR, Yang IH, Selariu A, Zhu H, Yee M, Goldstein RS. Retrograde axonal transport of VZV: kinetic studies in hESC-derived neurons. J Neurovirol, 2012, 18: 462-470

109 Sadaoka T, Yoshii H, Imazawa T, Yamanishi K, Mori Y. Deletion in open reading frame 49 of varicella-zoster virus reduces virus growth in human malignant melanoma cells but not in human embryonic fibroblasts. J Virol, 2007, 81: 12654-12665

110 Sadaoka T, Serada S, Kato J, Hayashi M, Gomi Y, Naka T, Yamanishi K, Mori Y. Varicella-zoster virus ORF49 functions in the efficient production of progeny virus through its interaction with essential tegument protein ORF44. J Virol, 2014, 88: 188-201

111 Sato H, Callanan LD, Pesnicak L, Krogmann T, Cohen JI. Varicella-zoster virus (VZV) ORF17 protein induces RNA cleavage and is critical for replication of VZV at 37 degrees $\mathrm{C}$ but not 33 degrees $\mathrm{C}$. $\mathrm{J}$ Virol, 2002, 76: 11012-11023

112 Uetz P, Dong YA, Zeretzke C, Atzler C, Baiker A, Berger B, Rajagopala SV, Roupelieva M, Rose D, Fossum E, Haas J. Herpesviral protein networks and their interaction with the human proteome. Science, 2006, 311: 239-242

113 Stellberger T, Hauser R, Baiker A, Pothineni VR, Haas J, Uetz P. Improving the yeast two-hybrid system with permutated fusions proteins: the varicella zoster virus interactome. Proteome Sci, 2010, 8: 8

114 Bohannon KP, Jun Y, Gross SP, Smith GA. Differential protein partitioning within the herpesvirus tegument and envelope underlies a complex and variable virion architecture. Proc Natl Acad Sci USA, 2013, 110: E1613-E1620

115 Zhou ZH, Chen DH, Jakana J, Rixon FJ, Chiu W. Visualization of tegument-capsid interactions and DNA in intact herpes simplex virus type 1 virions. J Virol, 1999, 73: 3210-3218

116 Cardone G, Newcomb WW, Cheng N, Wingfield PT, Trus BL, Brown JC, Steven AC. The UL36 tegument protein of herpes simplex virus 1 has a composite binding site at the capsid vertices. J Virol, 2012, 86: 4058-4064

117 Zhou ZH, Dougherty M, Jakana J, He J, Rixon FJ, Chiu W. Seeing the herpesvirus capsid at 8.5 A. Science, 2000, 288: 877-880

118 Grunewald K, Desai P, Winkler DC, Heymann JB, Belnap DM, Baumeister W, Steven AC. Three-dimensional structure of herpes simplex virus from cryo-electron tomography. Science, 2003, 302: 1396-1398

119 Guo H, Shen S, Wang L, Deng H. Role of tegument proteins in herpesvirus assembly and egress. Protein Cell, 2010, 1: 987-998

120 Mettenleiter TC. Herpesvirus assembly and egress. J Virol, 2002, 76: 1537-1547

121 Meckes DG Jr, Wills JW. Dynamic interactions of the UL16 tegument protein with the capsid of herpes simplex virus. J Virol, 2007, 81: $13028-13036$

122 Loomis JS, Courtney RJ, Wills JW. Packaging determinants in the UL11 tegument protein of herpes simplex virus type 1. J Virol, 2006, 80: 10534-10541

123 Klupp BG, Fuchs W, Granzow H, Nixdorf R, Mettenleiter TC. Pseudorabies virus UL36 tegument protein physically interacts with the UL37 protein. J Virol, 2002, 76: 3065-3071

124 Han J, Chadha P, Starkey JL, Wills JW. Function of glycoprotein e of herpes simplex virus requires coordinated assembly of three tegument proteins on its cytoplasmic tail. Proc Natl Acad Sci USA, 2012, 109: 19798-19803

125 Galea SA, Sweet A, Beninger P, Steinberg SP, Larussa PS, Gershon AA, Sharrar RG. The safety profile of varicella vaccine: a 10-year review. J Infect Dis, 2008, 197: S165-S169

126 Elliott G, O'Hare P. Herpes simplex virus type 1 tegument protein VP22 induces the stabilization and hyperacetylation of microtubules. J Virol, 1998, 72: 6448-6455 
127 Ohta A, Yamauchi Y, Muto Y, Kimura H, Nishiyama Y. Herpes simplex virus type 1 UL14 tegument protein regulates intracellular compartmentalization of major tegument protein VP16. Virol J, 2011, 8: 365

128 Tanaka M, Sata T, Kawaguchi Y. The product of the herpes simplex virus 1 UL7 gene interacts with a mitochondrial protein, adenine nucleotide translocator 2. Virol J, 2008, 5: 125

129 Walters MS, Kyratsous CA, Silverstein SJ. The RING finger domain of Varicella-Zoster virus ORF61p has E3 ubiquitin ligase activity that is essential for efficient autoubiquitination and dispersion of Sp100-containing nuclear bodies. J Virol, 2010, 84: 6861-6865

130 Zhu H, Zheng C, Xing J, Wang S, Li S, Lin R, Mossman KL. Varicella-zoster virus immediate-early protein ORF61 abrogates the IRF3-mediated innate immune response through degradation of acti- vated IRF3. J Virol, 2011, 85: 11079-11089

131 Sloan E, Henriquez R, Kinchington PR, Slobedman B, Abendroth A. Varicella-zoster virus inhibition of the NF- $\mathrm{B}$ pathway during infection of human dendritic cells: role for open reading frame 61 as a modulator of NF- $\kappa$ B activity. J Virol, 2012, 86: 1193-1202

132 Jacob T, Van den Broeke C, van Troys M, Waterschoot D, Ampe C, Favoreel HW. Alphaherpesviral US3 kinase induces cofilin dephosphorylation to reorganize the actin cytoskeleton. J Virol, 2013, 87: 4121-4126

133 Van den Broeke C, Radu M, Deruelle M, Nauwynck H, Hofmann C, Jaffer ZM, Chernoff J, Favoreel HW. Alphaherpesvirus US3mediated reorganization of the actin cytoskeleton is mediated by group A p21-activated kinases. Proc Natl Acad Sci USA, 2009, 106: $8707-8712$

Open Access This article is distributed under the terms of the Creative Commons Attribution License which permits any use, distribution, and reproduction in any medium, provided the original author(s) and source are credited. 